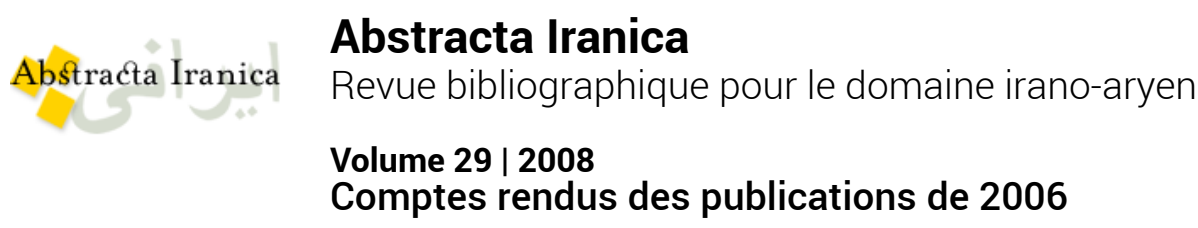

\title{
PRÉFACE - Abstracta Iranica 29 - 2006
}

Rémy Boucharlat, Poupak Rafii Nejad et Dominique Torabi

\section{(2) OpenEdition}

Journals

Édition électronique

URL : http://journals.openedition.org/abstractairanica/34002

DOI : 10.4000/abstractairanica.34002

ISSN : 1961-960X

Éditeur :

CNRS (UMR 7528 Mondes iraniens et indiens), Éditions de l'IFRI

Édition imprimée

Date de publication : 15 mai 2008

ISSN : 0240-8910

\section{Référence électronique}

Rémy Boucharlat, Poupak Rafii Nejad et Dominique Torabi, «PRÉFACE - Abstracta Iranica 29 $2006 »$, Abstracta Iranica [En ligne], Volume 29 | 2008, mis en ligne le 15 septembre 2008, consulté le 26 septembre 2020. URL : http://journals.openedition.org/abstractairanica/34002 ; DOI : https:// doi.org/10.4000/abstractairanica.34002

Ce document a été généré automatiquement le 26 septembre 2020.

Tous droits réservés 


\title{
PRÉFACE - Abstracta Iranica 29 - 2006
}

\author{
Rémy Boucharlat, Poupak Rafii Nejad et Dominique Torabi
}

1 Ce vingt neuvième numéro d'Abstracta Iranica, avec plus de 450 entrées, reflète une masse de publications relativement stable depuis quelques années: les domaines couverts varient un peu, soit en fonction de la plus ou moins grande abondance de documents, soit en raison de la disponibilité de nos collaborateurs. Ceux-ci, bien que très nombreux (66. pour ce numéro) travaillent bénévolement, prenant sur leur temps de recherche ou d'enseignement pour lire les ouvrages et rédiger les comptes-rendus. C'est grâce à eux que la revue existe et, si certains ouvrages importants peuvent nous échapper, cette année comme les autres, nous avons essayé de combler au mieux les lacunes des deux dernières années.

2 Cette livraison papier de la revue paraît, comme l'an dernier, après la version en ligne sur revues.org. Ce décalage désormais constant entre les deux versions nous conduit à privilégier comme date de parution celle de la mise en ligne.

3 La rétrospective en ligne des anciens numéros se poursuit (23 et 24 sont désormais sur le site), même si le calendrier promis en 2007 ne pourra pas être parfaitement respecté. L'indexation aussi souffre d'un certain retard: elle est plus longue à mettre en place que nous ne l'avions initialement prévu. Toutefois, tel qu'il est, le site de la revue est de plus en plus fréquenté, comme en témoignent les offres de collaboration via le site et les nombreux courriers adressés à la rédaction (demandes de renseignements sur les auteurs des ouvrages et ceux des comptes-rendus, ou même commandes des ouvrages recensés “!”). L'écho offert par internet prolonge ainsi efficacement la réputation que la revue avait acquise sous sa forme traditionnelle. L'importance de la diffusion et de la communication par internet, $d u$ fait des échanges et interrogations qu'il permet pourra conduire à une évolution de la forme de la revue. Pour préparer les changements éventuels et pour rendre la revue encore plus utile, toutes vos remarques sont les bienvenues. 
INDEX

Thèmes : Avant propos 